\title{
Interrelationship between integrated curriculum and thematic approach from ECDE to Grade Three
}

\author{
Singhi Lhomi \\ ECEC, Lalitpur, Nepal \\ Email: singithikepa@gmail.com
}

\begin{abstract}
This article attempts to provide the concept of Basic Level Education from early childhood to grade three and overview integrated curriculum and thematic approaches at this level. The main purpose of the study is to clarify the concept of integrated curriculum and the theme based approach. The data was collected from semi structured interview and focus group discussion using non-probability purposive sampling. As amended Education Act, from early childhood education up to Grade three is considered Basic Level and the children play the vibrant role to shape the rest of the human life. So integrated curriculum has been proposed for Basic Level education from class one to three in Nepal. On the basis of integrated curriculum, the thematic approach can be applied to deliver this curriculum. The core subjects like Maths and languages both Nepali and English can be taught separately but rest of the subject matters have been integrated in recent curriculum under 11 themes. This paper has been described from constructivist worldview. It contributes the significance and relevancy of thematic teaching approach from ECDE to grade three at Basic Level Education to implement the integrated curriculum. An integrated curriculum is a wellorganized and managed of various subjects within a single theme which enhances the students learning achievement through various activities. The curriculum which has been blended within theme-based approach would provide more exposure and learning experiences to the learners to achieve the life skills.
\end{abstract}

Keywords: Basic education, early childhood education, integrated curriculum, thematic approach, constructivist

\section{Introduction}

Basic education refers to the class from Early Childhood Education to class eight (Education Act 1971 amended in 2015). The Early Childhood Education possesses the child who has completed the age of four. According to the National Curriculum Framework (2018), the basic education has been categorized into three 
phases. They are basic education grade 1 to 3 , basic education grade 4 to 5 , basic education grade 6 to 8 (NCF, 2018, p.51). There are various thoughts about the definition of age groups by philosophers, educationists, theorists but it has been accepted that aged from 0-8 year is considered as Early Childhood Development phase. The span of this age group is in grade Early Childhood Education to grade 3. The span of this age group is taken as fundamental of human life. The core objective of this level is to develop holistically and to fulfill the gap between Basic Level's educations. Therefore, the objectives need to be fulfilled by launching the integrated curriculum through thematic based approach. Nepal is stepping forward to change in education. The concept of curriculum integration was originated in the late $1800 \mathrm{~s}$ with Herbartians, a movement named after German philosopher and educator Johann Friedrich Herbart. He developed the concept of correlating disconnected subject areas around themes. In the 1920s, John Dewey led the progressive movement; progressive education placed students' personal and social concerns at the center of curriculum (Petrosyan et al., 2005). This age group is significant because children will build their foundation from this level. We need to cater our education such a way so that the children would develop their competence. The competence contains that knowledge, skills, attitude based education. In our education system, the pedagogical approach is established as traditional and theory based culture. These kinds of methods and practices cannot fulfill the expectation of basic education.

On the other hand, the early years are significant period of human life and they need to explore and experience with activity based learning. The present era is the age of an innovative and emergence of science and technology which is creating the education more challenge to adjust globally. Due to this reason, Nepal government has drafted the curriculum based on based on knowledge, skill and attitude. As long as curriculum is revised, the methods and approaches also need to be changed. So the curriculum is conceptualized based on integration from ECDE up to grade 3 (Draft of National Curriculum Framework, 2018).

This sentence can be continued in previous paragraph. Thematic based approach implies the core subject like Maths, Language and Science but most of the others subjects will be integrated within a theme. The theme is a set of organized learning experiences such as programmes, courses, and other school-sponsored activities that provide students with exposure to a broad, predominant content theme (Finch et al., 1997). That would help to address the gap of knowledge and skill based on learning in education. 
According to Department of Education (2005), Early Childhood Development Curriculum Handbook, the main objectives of curriculum are to provide the opportunity for their holistic development, encourage them to build the sanitation habits, develop good manners and to prepare them for primary education. To achieve these goals the curriculum has been developed holistically including subject wise and focusing on development areas (Department of Education, 2005). The National Curriculum Framework (2018) has also emphasized the integrated curriculum from grade 1 to 3 and gradually it has planned to extend up to grade 8 basic level education. The teaching and learning activities in the basic level classrooms of Nepal emphasize more on rote learning and fact memorization of the content of the textbook. The curriculum, which does not address the diversity, teaching materials which are very limited and not in vernacular languages are the challenges of quality in education (Bhandari, 2015). In Nepal, it has been implemented the national curriculum for ECD since 2005. On the basis of this curriculum, the national minimum standard was formulated in 2010. It was revised in 2018. Our education system has focused on only cognitive area rather focusing on holistic development. The ECD curriculum states to implement the theme based teaching approach. The integrated curriculum has aimed to teach languages like Nepali and English and Maths separately whereas the rest of the subjects like science, creative art, moral education, life skills are planned to include in a core subject 'My Surrounding' as in an integrated curriculum. The integrated curriculum and connected learning, to develop the high level of thinking is demanded in recent global competition (Retnawati et al., 2017). The thematic approach is the holistic teaching approach where most relevant and appropriate methodologies can be included in this approach. Thematic approach is the learning strategies that have been proposed by many researchers and psychologists. The value of implementing the thematic learning is that students learn better because learning activities are initiated by problems that have been presented under selected themes. The thematic learning is an approach that is suitable for learners' development and recent educational practice (Retnawati et al., 2017). Likewise, the educationists John Dewey to Howard Gardener have emphasized the virtue of studying subject in a holistic and contextual way than in a vacuum (Ghimire, 2018). The contextual and integrated approach can scaffold the learners to consolidate their knowledge skills and attitude. Since Nepal Government has implemented the integrated curriculum in basic level education basically up to grade 3, the essence of thematic approach and integrated curriculum have been interlinked each other to implement the new curriculum and enhance quality education in Nepal. 
There are several motives to choose this topic. As I have faced and experienced in my teaching career that the students are being tired of listening to lectures and stuck on just text-based approach so the recent modern and postmodern age, the students can construct their knowledge based on their experience. And students have their own thinking pattern towards achieving education but they are restricted within formal setting which has limited the knowledge construction. Considering the above context, I would like to explore to answer the following research questions:

1. How do teachers and teacher educators' view towards integrated curriculum and thematic approach?

2. How are they interrelated each other in terms of teaching and learning?

3. How do integrated curriculum and thematic approach implement in classroom to enhance learners' competence (knowledge, skills and attitude) development?

\section{Theoretical Framework}

In my study, I have preferred constructivist theory. It is a theory of epistemology that argues humans generate knowledge and meaning from the experience and knowledge can be constructed based on individual interpretation so that it can be the focal source of knowledge (Creswell \& Poth, 2018). The process of learning takes place when the learner involves in interaction, active learning activities and more space to provide for creativity. Creswell (2014) mentioned that constructivist believes the meaning is multiple realities (Kuyini \& Kivunja, 2017) and various so it leads the researcher to search the complexity of opinions rather than just narrowing into limited ideas. The integrated curriculum has given space to create multiple knowledge for learners. The knowledge does not exist in its own right but knowledge is constructed (Taylor \& Medina, 2013) and reconstructed by human beings as they interact and engage in interpretation (Pant, 2016). So, the project based curriculum requires project based approach. It is also called an integrated approach. It contains maths, science, social, language, creative arts, etc. If we teach through project based approach, it can impart the intended knowledge and skills to learners. As the concept of connected model, the fragmented areas and concept can be connected within each subjects area connecting one topic, one skills, one concept to next level of it (Ghimire, 2018). This can help to make creative and competent. The learners can tackle and cope with the recent development in educational phenomena. It would enhance the learner's attitude towards the education and they will survive and adjust in complex and competitive world. 


\section{Methods}

In order to undertake this research, the qualitative design and constructivism worldview have been used. I have used non-probability purposive sampling method to collect the data. And the data for the research have been gathered through semi structured interview, observation and focus group discussion. For the primary data collection, the participants of my research were selected from Lalitpur district. They were three teacher educators of preprimary and basic level of Early Childhood Education Centre and six teachers from school level especially who are teaching up to grade 3 whereas the secondary data have been collected by consulting academic journal articles, books and data based eBooks.

As I have prepared for the data collection, I made clear about ethical issues regarding their information shared with me. I built relationship with the respondents and began to collect the data. I used semi structured interview and observation as tools to collect the data. After collecting the data, I transcribed the data, coded the data and eventually developed themes for my research. The data obtained through interview, observation, focus group discussion were analyzed and interpreted according to the themes.

\section{Results and Discussion}

As I interviewed and had a focus group discussion with the teacher educators and teachers and observation done in different schools, I have generated the various themes based on the coded themes, and themes which have been mentioned and frequently repeated by respondents were analyzed and discussed. The following themes have been categorized for interlinked between integrated curriculums and thematic based approach from ECDE to grade 3.

\section{Integrated Curriculum and Subject based Curriculum}

As I asked the questions regarding the integrated curriculum, one of the respondents remarked that government they do not talk about totally integrated and thematic approach. And if you do integrated thematic approach you do not need to talk about language, math, and science separately. These all can be taught in depth within activities.

According to the NCF (2018), the integrated curriculum is considered as subject and combined the subjects like social science, creative arts, and moral education. Similarly, in real practice, most of the preschools/ECDE centres have 
textbooks and separate book named as the theme based book. It was found that many schools are still not clear about what theme based teaching and integrated curriculum is in real sense but they still consider theme as subject based approach. Alghamdi (2017) mentioned that conventional curricular presents and teaches the subject separately and have a few connections with other subjects. Another respondent puts her views that ... in theme approach separate subject teaching does not require the subjects like language, math and science but it can be linked it activities as project based approach. It shows that the theme is not considered as separate subject but it is an integrated approach. The term "integrated curriculum" also defined the project approach in the 1920s, the central curriculum movement in the 1930s and the problem-based core curricula of the 1940s and the 1950s. The students seem enthusiastic for their learning, they talk about three different aspects: learning content, learning social skills, and doing interesting activities (Petrosyan et al., 2005).

In this regards, from the Focus Group Discussion of teacher educators responded as: ... is form of the combination of various subjects in single topic. There may be single topic and it can foster different skills. There may be single theme like 'Me and my family. It can develop the holistic development and skills.

So it was justified that the integration is inclusion of different subjects. It helps to enhance the holistic development of children. The respondent agreed for the above statement and she adds, ... integrated curriculum means the all subject matters like science, math, languages which can be combined or it can be also called as cross curricula. The integrated means the combination of all areas of learning. Integrated curriculum is new concept that covers literacy and numeracy skills taught across the curriculum, assessment of learning, differentiated instruction (Yvonne, 2015). The new curriculum has to be implemented with new approach that is thematic approach. This approach is scientific learning, problem based learning, and project based learning (Retnawati, 2017) teaching and learning process cannot be fruitful by the teacher knowledge and belief but it can be immerged and the learners can also produce through his/ her ideas and experience and proper exposure and guidance.

As I interviewed regarding the subject based approach, the respondent viewed If we teach in traditional way and subject based, it might cover only academic but the holistic development can be possible through integrated curriculum. If we focus on integrated curriculum it develops holistic development and can address different learning styles like visual, audio and kinesthetic and the multiple intelligence. It 
was found that the subject teaching can just address the academic aspect rather than overall development of children. Likewise, integrated curriculum can cover all other subjects in combined model so that the learners' learning styles are recognized and their areas of interest and need can be inclusive in integrated curriculum through thematic approach.

\section{Misconception of Integrated Curriculum and Thematic Approach}

The integrated curriculum concept is not clear for the teachers. They are teaching theme as a subject rather than an approach. So it can be called as semi integrated curriculum. In fact the subject based teaching does not require to teach separately.

Regarding this matter, one of the teachers' educators mentioned that ... lack of training, the teachers are unknown about to implement integrated curriculum and could not integrate the various activities like songs, rhymes, story, games and creative activities to teach in thematic based. They are not aware of teaching with thematic approach.

Similarly, another respondent indicates ... implementing the new approach and curriculum is because of the fear for change. People are looking for the change in education and but mostly they do not know how to change it. It has justified that many people are looking for change but to implement the thematic approach is a matter of fear.

The thematic curriculum is a set of organized learning experiences such as programmes, courses, and other school-sponsored activities that provide students with exposure to a broad, predominant content theme (Finch et al., 1997). The integrated curriculum is an organized and combined way of developing curriculum where the students can experience various activities. Finch et al. (1997) mentioned the importance of thematic based curriculum so it can serve as a bridge to unite school- and work-based learning experiences. They further put forward their views that thematic curriculum can allow the students more opportunities to learn through contextualized learning experience (Finch et al., 1997).

As the teacher stated It does not mean that the subjects are not excluded. We should not focus on academic for young children. For the small children it is not good instead they have to know their surrounding and environment by exploring and it can be possible through theme. 
The misconception of thematic approach is still in the teachers. It was found that they thought if they do implement the thematic approach means excluding subjects. But it can be included within theme. As the ECD curriculum there found mainly two parts like developmental areas and subject wise areas. In terms of nature, this can be called semi-integrated curriculum rather full. It was found that teachers have difficulty to implement the thematic based teaching fully due to lack of training, they prefer subject teaching.

Regarding the matter, still parents have misconception about this approach and modality of this kind of curriculum and a respondent puts the opinion The parents might have complained and disagreed about project/theme based learning. But in reality the children can learn many things by involving in depth.

\section{Role of Training to implement Integrated Curriculum}

Training can play the crucial role to implement the new things and can enhance self-confidence. Training focuses on the immediate period to support to solve the current issue and problems on employees' skills which will help to work in future (Adhikari, 2019). It was also found that the teachers got fatigues to prepare lessons based on project. Still lack of training and low self-steam they are found afraid of approaching new practice. The teacher educators responded that The teachers have fear of implementing the new approach and curriculum. And realized that the teachers mostly got hesitate to try out something new. It was found that integrate curriculum and theme based approach have helped to build up a good relationship between them. And it was also found that the teachers are afraid of attempt to do new thing due to lack of proper skills.

Likewise, regarding the proper implementation of thematic approach and curriculum the role of teachers' training, the teacher mentioned that ...grade teaching can be good relationship between teacher and student. Still doubt that all teachers can able to apply integrated approach. So, teachers need to have training and a good education and need to update and carry on research by books and look for internet. It was also found that the integrated curriculum can be implemented through thematic approach and it seems it is possible in Nepal. But the challenge was found in lacking of the trained teachers. The way of teaching has to be changed the way of teaching to teach integrated ways. It was also found that the mostly teachers get afraid of teaching grade teaching because they are just trained up teaching single subject only. They need to have good planning, classroom organization. They need to know how to conduct small group teachings. The children have to help 
themselves. They are in small group teaching and they can rotate and can do different activities. They can go out and play. They can give those tasks and play freely. They take creativity of the teachers and understanding what are the major goals and developmental milestone they have to learn. Integrated teaching means good management and good preparation and good knowledge of the development of the each child and what they should, where they are, where they need to grow. Yvonne (2015) remarks the usefulness of new integrated curriculum that this curriculum is to reveal the prospective teachers were more effective in meeting the needs of all students while implementing the new thematic, integrated curriculum when trained compared to the prospective teachers implementing the curriculum without training.

\section{Interlink between Integrated Curriculum and Thematic Approach}

Data obtained from interview with teachers and FGD with teacher educators indicated that thematic approach is one way of teaching approach. These sorts of approaches have been aimed to implement in government documents and curriculum (Department of Education, 2005). One of the respondents stated as Thematic approach is topic in which we work around. Even in some grade, theme activities can be less. From primary teachers need to have proper guidance to implement it. They should have a good guideline for teaching. The theme like 'Understanding the World', can integrate the science, social, art, technologies, manner and moral education. The integrated approach does not mean teaching as subject but there should have real integration.

The thematic approach is the approach which can integrate the ideas and subjects within a single concept. Prince Edward Island Department of Education (2008) states that the curriculum integration provides educators with a practical approach to connect outcomes in a meaningful way. It is a holistic approach that reflects the real world and prepares children for lifelong learning. Integration is above all a practice that is not learned or taught, but is lived. An integrated thematic curriculum indicates a modification in teaching and learning. The modification has occurred when students do not entirely experience subjects as distinct, but rather within themes, placed in context and logically organized and linked to real life situations.

Regarding the interrelation between theme and integrated curriculum the respondents remarked as Theme is part of integrated curriculum. Integrated and cross curricular are called same. The obtained data indicated that the theme is the part of integrated curriculum. Likewise, teacher educators agreed and mentioned 
that Integrated approach is the combination of various theorists' views which can be combined together. The best of teaching integrated curriculum is play way method and thematic approach. It indicates that the integrated curriculum is formulated by combining the diverse theorist's views. The best of implementing it can be the play way methods. Curriculum designers should consider the thematic units, issues-based learning, inquiry-based learning, and problem-based learning as their underlying method of integration in curriculum (Alghamdi, 2017).

Another participant stated that the thematic approach is basically used in ECD/preschool up to 1, 2, 3 classes in primary school. It might be based on monthly and weekly based and in integrated curriculum they get in-depth understanding ... single topic which includes different subject matters within a topic. The teachers have to prepare well before ahead and have to do more homework. The statement proved that the integrated curriculum and theme based teaching and play way method are interlinked one another. They have good ways and methods to implement curriculum. It was also found that the integrated curriculum can impart depth understanding in subjects but it was found to cost much time and effort by teachers. From the date it is connected that an integrated thematic curriculum is not a new concept, best practice advocates that people gain knowledge best when learning in the context of a coherent "whole," making connections to real-world situations (Yvonne, 2015).

\section{Policy to implement Integrated Curriculum and Thematic Approach}

The government is the apex body to implement the curriculum as per the demand of time and interest of students. It was found that the developing country like Nepal, the society which is looking for changing needs may take place if there is implementation of curriculum and it is also required the most influential factors to apply thematic curriculum in education of the country (Mabirizi,2017). As the teachers educators and teachers viewed "Our government has proposed to implement integrated curriculum but they do not have clear concept. They are going to launch it as a pilot project in Nepal. As I experienced our county is trying to adopt from the other countries. The way of teaching has been changed now and before 10 years ago". So as curriculum is ongoing process of development, revision and up to date (Basic Level Grade 1 -3 Curriculum, 2018). As NCF (2018) our government has planned to implement the integrated curriculum from 2019 as a pilot project. The statement shows that regarding new change our government is stepping forward to 
bring the change in Nepali Education system and looking for change in education. Likewise, the FGD group teachers' educators mentioned that "... develop activity based resources based on curriculum of Nepal Government to make practical and child friendly education". The group of educators have been working for child friendly resource development which can address the need of learners. In this regards one of the respondent mentioned that "... launching integrated curriculum in $21^{\text {st }}$ century to enhance the collaborative skills, communication information and digital literacy, leadership skill, to produce civilized. We can develop holistically if we implement integrated curriculum."

The integrated curriculum can enhance knowledge as well the skills required for learners in the $21^{\text {st }}$ century and future education. According to Department of Education (2005), early childhood development handbook curriculum has been designed according to the concept of thematic approach. And it has focused on holistic development of children through theme based teaching approach. He further mentions that the thematic integrated instruction puts the teaching of cognitive skills (reading, mathematics, science, writing, social studies and other subjects identified) in the context of a real-world subject that is both specific enough to be practical, and broad enough to allow creative exploration. (Yvonne, 2015).The integrated curriculum has made a connection and a primary focus is student achievement. It performances as a bridge to increased student achievement and engaging, relevant curriculum.

\section{Conclusion}

The interrelationship between the thematic approach and integrated curriculum seems strongly visible as the researcher carried out the research based on his experience and interview with different level of people around. The integrated curriculum concept has been emerged in developing countries like Nepal. So it has a lots of positive benefits. Since the age of early years and basic level children aged of $8 / 9$ can learn through exploration, experiment and based on project based teaching. Human has two kinds of memory, one is long term and another one is short term. The thematic approach comforts to retain the knowledge in long term memory more. The project based approach and thematic approach can cover the holistic areas by involving hands on experience. Since ECD curriculum has already launched theme 
based approach, the pilot project for basic level has also launched from this year. It would help to reduce the overload of textbooks in primary school. The integrated curriculum has emerged by the concept to link the different skills, subject within a single theme. So the integrated curriculum and thematic approach go simultaneously in pedagogical process. The expectation of quality education would be fulfilled through implementing the integrated curriculum and associating with project based thematic approach. As respondents and participants of FGD mentioned, the soft skills based human and civilized person, family and society, nation and globally accepted education can be possible through implementing the integrated curriculum and theme based approach.

\section{References}

Adhikari, S.P. (2019). Practices of early childhood development curriculum preparation, Interdisciplinary Research in Education, 4 (1). Kathmandu: Central Department of Education.

Alghamdi, A.K.H. (2017). The effect of and integrated curriculum on student achievement in Saudi Arabia. Saudi Arabia: Imam Abdulrahman Bin Faisal University, EURASIA Journal of Mathematics Science and Technology Education, 13(9):6079-6100 DOI: 10.12973/ eurasia.2017.01051a

Bhandari, B. M. (2015). Challenges of education in Nepal post 2015. Retrieved from https://www.academia.edu/9957161/Challenges_of_Education_in_ Nepal_post_2015.

Creswell, J. W. (2014). Research design qualitative, quantitative and mixed methods approaches. Thousand Oaks, CA: SAGE.

Creswell, J.W. \& Poth, C.N. (2018). Qualitative inquiry and research design choosing among five approaches. Thousand Oaks, CA: SAGE.

Department of Education (2005). Early childhood development handbook curriculum. Bhaktapur: Department of Education.

Finch, R.C., et al. (1997). Designing the thematic curriculum: An all aspects approach MDS-956. National Center for Research in Vocational Education. U.S Department of Education. 
Ghimire, R.P., (2018). Understanding an integrated curriculum. Siksa Biannual Educational Journal, 46(1). Bhaktapur: Curriculum Development Centre, Government of Nepal

Government of Nepal (2018). Draft of national curriculum framework (NCF). Baktapur: Department of Education.

Government of Nepal, (1971) Education act (1971.) Ninth amendments 2015.

Kathmandu: Kanuni Kitab Vyawasthapan Samitee.

Kuyini, A.B., \& Kivunja, C. (2017). Understanding and applying research paradigm in educational context. International Journal of Higher Education. 6(5).

Mabirizi, M. (2017). Challenges facing the implementing of thematic curriculum in lower primary schools in Uganda a case of Nabingoola sub-county, Mubende district. Master degree research report.Uganda: Nkumba University.

Pant, P. R. (2016). Social Science research and thesis writing. Kathmandu: Buddha Publications.

Petrosyan, S. et al. (2005). Integrated social studies instruction, curriculum design and model an educator's handbook. Wahsington: International Research \& Exchanges Board.

Prince Edward Island, (2008). Early childhood education and care. Canada:

Department of Education. Retrieved from https://childcarecanada.org/ sites/default/files/ECEC08_PE.pdf

Retnawati, H et al. (2017). Teachers' difficulties in implementing thematic teaching and learning in elementary schools. The New Educational Review, 48(2), 16.doi:10.15804

Taylor, P. C., \& Medina, M. N. D. (2013). Educational research paradigms: From positivism to multi paradigmatic. The Journal of MeaningCentered Education. 1 (2). Retrieved 04/19/2019 on from http:// www.meaningcentered.org/journal/volume-01/educational-researchparadigms-frompositivism-to-multiparadigmatic

Yvonne, J.J. (2015). A “new" thematic, integrated curriculum for primary schools of Trinidad and Tobago: A paradigm shift. International Journal of Higher Education, 4(3), 172. doi:10.5430 